\title{
Physical and Chemical Compatibility of Extended- Release Triamcinolone Acetonide (TA-ER) with Common Local Anesthetics
}

\author{
J. Derek Jackson · Lindsey Cotton • Melinda Turkington • \\ Daniel Leblanc $\cdot$ Scott Kelley
}

Received: December 4, 2018 / Published online: January 31, 2019

(C) The Author(s) 2019

\begin{abstract}
Introduction: Intra-articular (IA) corticosteroids are used extensively for the treatment of patients with knee osteoarthritis pain. In clinical practice, local anesthetics are frequently combined with corticosteroids prior to IA injection to provide rapid-onset analgesia. From this common practice there is no evidence to suggest that the addition of local anesthetics to corticosteroid preparations, including triamcinolone acetonide (TA), alters the physical properties or efficacy of the corticosteroid. Triamcinolone acetonide extended-release (TA-ER, formerly FX006) is a novel, microsphere-based TA formulation that demonstrated analgesic efficacy in phase 2 and 3 randomized controlled trials.

Methods: The current study assessed the compatibility of TA-ER and lidocaine, ropivacaine, and/or bupivacaine in vitro. The TA-ER and local anesthetic mixtures were assayed for changes in syringeability, $\mathrm{pH}$, particle size, percentage free drug, purity, and appearance compared with TA-ER alone.
\end{abstract}

Enhanced Digital Features To view enhanced digital features for this article go to https://doi.org/10.6084/ m9.figshare.7593875.

J. D. Jackson $(\bowtie) \cdot$ L. Cotton $\cdot$ M. Turkington ·

D. Leblanc · S. Kelley

Flexion Therapeutics, Inc., Burlington, MA, USA

e-mail: djackson@flexiontherapeutics.com
Results: By these measures, the combination of local anesthetics with TA-ER did not negatively impact the chemical or physical properties of TA-ER when compared to TA-ER controls.

Conclusion: These results demonstrate that lidocaine, bupivacaine, and ropivacaine are physically and chemically compatible with TAER, suggesting that local anesthetic solutions can be added to TA-ER preparations in clinical practice without adversely affecting TA-ER in vitro product characteristics.

Funding: Flexion Therapeutics, Inc.

Keywords: Corticosteroid; Drug combinations; Injection; Intra-articular; Lidocaine; Local anesthetic; Osteoarthritis; Triamcinolone acetonide extended-release

\section{INTRODUCTION}

Knee osteoarthritis (OA) is a degenerative joint disease associated with chronic pain, resulting in reduced health-related quality of life (HRQoL) compared with healthy individuals, and a high rate of disability [1-3]. Approximately 30 million adults in the USA have OA and at least $19 \%$ of individuals over the age of 45 are affected by knee OA $[2,4]$. There is no cure for $\mathrm{OA}$, but there are pharmacologic treatment options available to reduce pain, including intra-articular (IA) injections of corticosteroids and local anesthetics [5-8]. 
IA administration of local anesthetic is used primarily during or after knee arthroscopy, but has also been used for the short-term pain management of knee $\mathrm{OA}$ and to aid in the diagnosis of local versus referred pain $[6,9]$. Commonly used local anesthetics include lidocaine, bupivacaine, ropivacaine, and procaine [6]. Local anesthetic injection is associated with rapid onset of analgesia; however, rapid absorption, distribution, and clearance from the injection site result in a short duration of pain relief $(\sim 4 \mathrm{~h})$ thereby limiting the use of local anesthetics in the management of chronic OA pain $[6,10-14]$. The addition of a vasoconstrictor, such as epinephrine, can increase the duration of local anesthesia, but is contraindicated for use in IA injections $[6,15]$. The rapid onset of analgesia provided by local anesthetics makes them ideal candidates for combination with slower onset but longer-acting IA injection drugs, such as corticosteroids.

Corticosteroids used for the treatment of OA include dexamethasone, betamethasone, methylprednisolone, and triamcinolone acetonide (TA) $[9,16]$. Corticosteroids are prepared as solutions or crystalline suspensions, with the most commonly used corticosteroids for IA injections being the crystalline suspension of TA and the solution formulations of prednisolone and methylprednisolone [16]. IA corticosteroids such as TA are used extensively for the treatment of knee OA and are commonly combined with local anesthetics in clinical practice [7-9].

Addition of local anesthetics to corticosteroid for IA injection provides rapid pain relief $[6,17-19]$. The rapid onset of analgesia is useful for reducing periprocedural discomfort and, in certain situations, can help clinicians differentiate local and referred joint pain $[6,9,17]$. The volume of local anesthetic used varies between physicians, with typical IA knee injection volumes of between $5 \mathrm{~mL}$ and $10 \mathrm{~mL}$ of combined local anesthetic and corticosteroid mixture $[7,9,16,20-22]$. In a survey of 506 rheumatologists, $65.9 \%$ reported that they combine local anesthetic in the syringe with corticosteroid when injecting the knee [23]. The most common reasons provided by physicians for combining local anesthetic with corticosteroids prior to injection were to provide immediate pain relief, to dilute or increase volume of steroid preparation, and to decrease post-injection flare [23]. Multiple previous studies have established the compatibility of standard corticosteroids mixed with local anesthetic and these combinations are frequently used in clinical studies, with the choice of local anesthetic and corticosteroid used for injection determined by clinical preference $[6,7,16,19-22,24-26]$.

Triamcinolone acetonide extended-release (TA-ER) is a novel formulation of TA in poly (lactic-co-glycolic acid) microspheres, which maintains prolonged concentrations of TA in the joint compared to standard TA crystalline suspension (TAcs) [27]. TA-ER $32 \mathrm{mg}$, in a standard, approved injection volume of $5 \mathrm{~mL}$, has demonstrated rapid, substantial, and durable pain relief in patients with knee OA [28-30]. To provide patients with analgesia during and immediately following IA injections, clinicians may desire to add local anesthetic to TA-ER injection solutions. As there is currently no data available in the literature regarding the suitability of combining TA-ER and local anesthetics, it is necessary to perform studies evaluating the compatibility of TA-ER and local anesthetic mixtures [31]. Because local anesthetics are rapidly distributed and cleared from the injection site, and since prior studies have established the compatibility of local anesthetics and corticosteroids in vitro and in vivo, the present study evaluated the impact of mixing lidocaine, ropivacaine, and/or bupivacaine on the chemical and physical properties of TA-ER prior to intra-articular injection.

\section{METHODS}

\section{Sample Preparation}

In this compatibility study the local anesthetics mixed with TA-ER (32 mg) were lidocaine hydrochloride solution (1\%; Hospira, San Jose, California, USA), bupivacaine hydrochloride solution (0.25\%; Hospira, San Jose, California, USA), and ropivacaine hydrochloride solution (0.5\%; Fresenius Kabi USA, Lake Zurich, Illinois, USA). 
The TA-ER suspensions were prepared as described in the marketed product instructions for use, with the full contents of each $32 \mathrm{mg}$ TAER vial being dispersed in $5 \mathrm{~mL}$ of TA-ER diluent [32]. TA-ER diluent is an aqueous diluent of $\mathrm{pH}$ between 4.5 and 7.5 containing normal saline for tonicity and a small amount of surfactant to aid in product wetting and dispersion. Six product suspension combinations were tested: (i) $5 \mathrm{~mL}$ TA-ER suspension "undiluted" (control); (ii) $5 \mathrm{~mL}$ TA-ER suspension and $5 \mathrm{~mL}$ (additional) TA-ER diluent; (iii) $5 \mathrm{~mL}$ TA-ER suspension and $5 \mathrm{~mL}$ lidocaine; (iv) $5 \mathrm{~mL}$ TA-ER suspension and $5 \mathrm{~mL}$ bupivacaine (v) $5 \mathrm{~mL}$ TAER suspension and $5 \mathrm{~mL}$ ropivacaine; and (vi) $5 \mathrm{~mL}$ TA-ER suspension and $2 \mathrm{~mL}$ lidocaine, $1.5 \mathrm{~mL}$ bupivacaine, and $1.5 \mathrm{~mL}$ ropivacaine.

The suspension combinations were prepared by drawing a full dose $(5 \mathrm{~mL})$ of reconstituted TA-ER into a 10-mL syringe followed by drawing $5 \mathrm{~mL}$ of local anesthetic or diluent. Once combined, the syringe contents were mixed by multiple inversions and stored for $30 \mathrm{~min}$ at ambient room temperature. Prior to analysis, the syringe contents were remixed by inversion to re-establish a homogenous suspension.

Mixtures were freshly prepared in triplicate. Syringeability, $\mathrm{pH}$, particle size, and optical microscopy were assessed using one set of triplicate preparations, with high-performance liquid chromatography (HPLC) analysis of purity and percentage free drug assessed using a separate set of triplicate preparations.

\section{Syringeability and pH Assays}

After the product mixtures had been stored for $30 \mathrm{~min}$ and then remixed, any residual air or foam that could result from mixing of the solution performed more vigorously than a gentle swirl was ejected from the product needle and a new 21-gauge $\times 1.5$-inch needle was attached to the syringe. Once again, the syringe was inverted to ensure the contents were well mixed. With firm and constant pressure applied by the thumb to the plunger, the contents of the syringe were injected into a scintillation vial to be used for $\mathrm{pH}$ measurement. Clogs were defined as the complete stoppage of the flow of suspension through the needle. A clog during injection was recorded as a failure and results were recorded as pass/fail.

Following this syringeability test, the $\mathrm{pH}$ of the sample preparations $\left(\sim 25^{\circ} \mathrm{C}\right)$ was tested using a calibrated pH meter (Orion STAR, A214). Each sample was measured in duplicate, and the average of the two readings was used to calculate the reported mean for each preparation. A total of three preparations were used to determine the mean response and standard deviation $(n=3)$.

\section{High-Performance Liquid Chromatography}

Drug purity and percentage free drug were measured using a proprietary validated reversed-phase gradient HPLC method. The chromatographic equipment used was an Agilent 1260 series instrument with diode array UV detection. The HPLC instrument was fitted with a functionalized mixed-mode C18 column $(150 \mathrm{~mm} \times 4.6 \mathrm{~mm}$, particle size $3 \mu \mathrm{m})$. The injection volume was $20 \mu \mathrm{L}$.

Standard solutions of TA (USP, Rockville, Maryland, USA) were prepared in dimethyl sulfoxide (DMSO) with subsequent dilution in a water/acetonitrile/formic acid HPLC diluent to achieve a final TA concentration of $0.2 \mathrm{mg} / \mathrm{mL}$.

Samples were prepared by harvesting drug product particles using centrifuge filtration. The filtrate was collected and dried at $30^{\circ} \mathrm{C}$ for $1 \mathrm{~h}$, with further drying at $25^{\circ} \mathrm{C}$ overnight as necessary. Once dried, sample particles were dissolved in DMSO with subsequent dilution in HPLC diluent to a final TA concentration of $0.2 \mathrm{mg} / \mathrm{mL}$. Impurities were identified on the basis of the retention time of known compounds and quantified as percentage weight using validated response factors. The percentage free drug in each TA-ER \pm local anesthetic preparation was assessed by analyzing the supernatant from the centrifugation step of the impurity sample preparation. 


\section{Particle Size Determination}

Particle size was evaluated using a Malvern Mastersizer 3000 Hydro MV Unit (Malvern, UK). A $0.1 \% \mathrm{v} / \mathrm{v}$ polysorbate 80 and water solution was used as the sample dispersant. Approximately $50 \mathrm{mg}$ National Institute of Standards and Technology (NIST) traceable Glass Sphere Particle Size Standards $(20-50 \mu \mathrm{m})$ were used for standard calibration and analysis. Following the 30 -min incubation, the TA-ER \pm local anesthetic mixtures were centrifuged, and particles harvested on a centrifuge filter. The solids were added to the particle sizer until the required light obscuration was achieved and then the samples were analyzed.

\section{Optical Microscopy}

The impact of mixing local anesthetics with TAER with respect to particle aggregation or agglomeration was qualitatively assessed by light microscopy. A 1-mL aliquot of each TA-ER control and TA-ER + local anesthetic preparation was evaluated using an Olympus BH-2 microscope at $\times 100$ magnification with digital image capture achieved using a Canon PowerShot G7 PC1210 equipped with a 58-mm microscope adapter. Some magnification variation occurred during image collection and processing, so no scale indications are provided. Because these images are for qualitative assessment the absolute scale of images was not critical to data interpretation.

\section{Compliance with Ethical Guidelines}

This article does not contain any studies with human participants or animal studies performed by any of the authors.

\section{RESULTS}

\section{Syringeability and pH Assays}

All samples passed the syringeability test, with no clogs observed (Table 1).
Table 1 Syringeability and $\mathrm{pH}$ measurement

\begin{tabular}{lll}
\hline Sample $^{\mathbf{a}}$ & Syringeability & $\begin{array}{l}\text { pH } \\
(\text { mean } \pm \text { SD) }\end{array}$ \\
\hline Control & Pass & $6.6 \pm 0.3$ \\
$+5 \mathrm{~mL}$ diluent & Pass & $6.9 \pm 0.1$ \\
$+5 \mathrm{~mL}$ lidocaine & Pass & $6.4 \pm 0.1$ \\
$+5 \mathrm{~mL}$ bupivacaine & Pass & $6.4 \pm 0.2$ \\
$+5 \mathrm{~mL}$ ropivacaine & Pass & $6.2 \pm 0.2$ \\
$+5 \mathrm{~mL}$ mixed local & Pass & $6.3 \pm 0.1$ \\
anesthetics & & \\
\hline
\end{tabular}

$S D$ standard deviation

a $n=3$ replicates per sample type

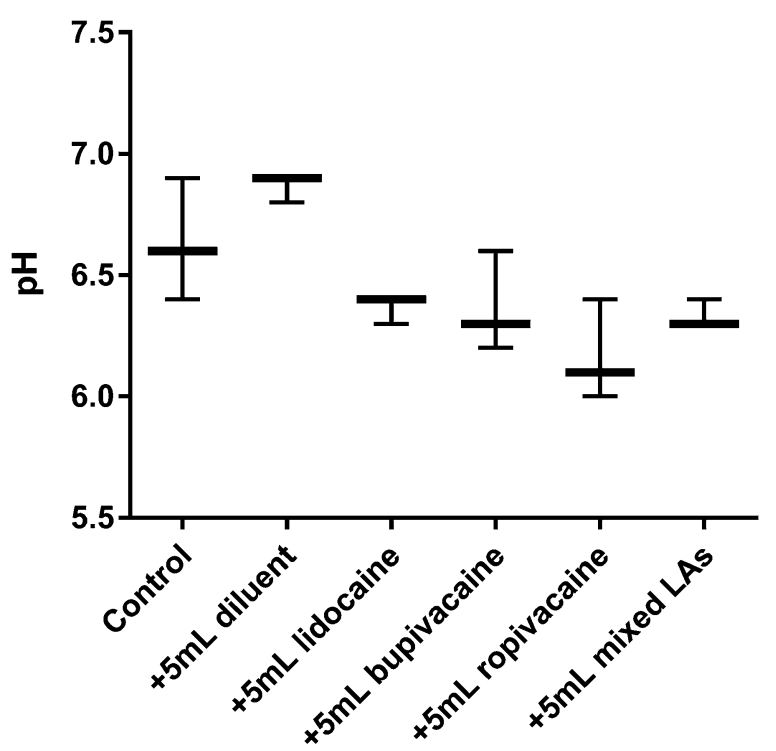

Fig. 1 Suspension $\mathrm{pH}$ of TA-ER \pm local anesthetic combinations. $L A$ local anesthetic, TA-ER extended-release triamcinolone acetonide

Summary data for $\mathrm{pH}$ determinations are provided in Table 1 and Fig. 1. Values ranged from $\mathrm{pH} 6.2$ to 6.9. As expected, because the TAER diluent is not buffered for $\mathrm{pH}$ control, the suspension $\mathrm{pH}$ is slightly lowered in mixtures of TA-ER with local anesthetic. This reduction is minor, within $1 \mathrm{pH}$ unit, and well within typical product specifications for a parenteral product [33]. 
Table 2 Purity and free drug analysis

\begin{tabular}{lllll}
\hline Sample $^{\mathrm{a}}$ & $\begin{array}{l}\text { Purity } \\
(\% \pm \mathbf{~ S D})\end{array}$ & $\begin{array}{l}\text { Largest individual impurity } \\
(\% \pm \text { SD })\end{array}$ & $\begin{array}{l}\text { Total impurities } \\
(\% \pm \mathbf{S D})\end{array}$ & $\begin{array}{l}\text { Free drug } \\
(\% \pm \text { SD })\end{array}$ \\
\hline Control & $98.9 \pm 0.3$ & $0.40 \pm 0.12$ & $1.1 \pm 0.3$ & $0.1 \pm 0.0$ \\
$+5 \mathrm{~mL}$ diluent & $98.9 \pm 0.2$ & $0.35 \pm 0.05$ & $1.1 \pm 0.1$ & $0.1 \pm 0.0$ \\
$+5 \mathrm{~mL}$ lidocaine & $98.7 \pm 0.0$ & $0.45 \pm 0.03$ & $1.3 \pm 0.0$ & $0.1 \pm 0.0$ \\
$+5 \mathrm{~mL}$ bupivacaine & $98.9 \pm 0.2$ & $0.38 \pm 0.08$ & $1.1 \pm 0.2$ & $0.1 \pm 0.0$ \\
$+5 \mathrm{~mL}$ ropivacaine & $98.8 \pm 0.0$ & $0.41 \pm 0.02$ & $1.2 \pm 0.0$ & $0.1 \pm 0.0$ \\
$+5 \mathrm{~mL}$ mixed local & $98.8 \pm 0.1$ & $0.40 \pm 0.06$ & $1.2 \pm 0.1$ & $0.1 \pm 0.0$ \\
\hline
\end{tabular}

$S D$ standard deviation

${ }^{\text {a }} n=3$ replicates per sample type

\section{High-Performance Liquid Chromatography}

A summary of data is provided in Table 2 and Fig. 2. No statistically meaningful differences in product purity or percentage free drug were observed across all sample types. The largest individual impurity was the same species across all sample types and was in the range of typical product and method variability.

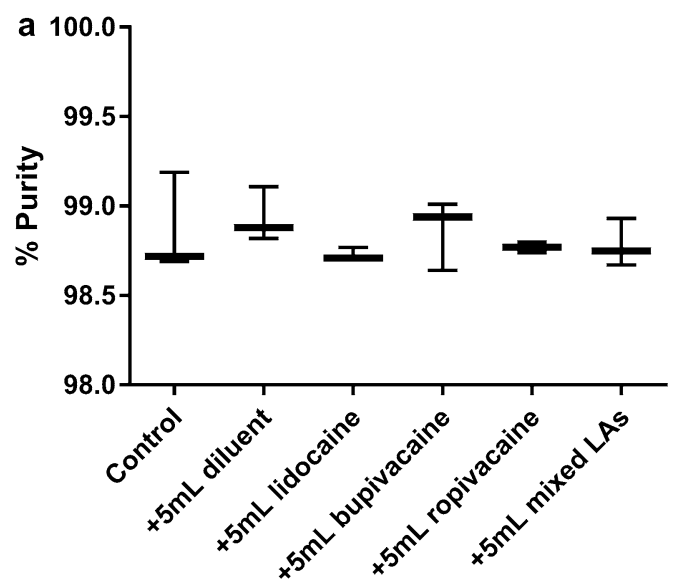

Fig. 2 Suspension (a) and primary individual purity (b) of TA-ER \pm local anesthetic combinations. $L A$ local anesthetic,

$T A-E R$ extended-release triamcinolone acetonide

Particle size data are summarized in Table 3 and Fig. 3. No statistically meaningful differences were observed for any of the volume distribution fractions measured. The greatest variability was observed in the $\mathrm{D}_{90}$ fraction, with maximum variability in the controls, indicating no effect from the local anesthetic solutions when mixed with TA-ER. The variability observed is consistent with typical method performance [34].

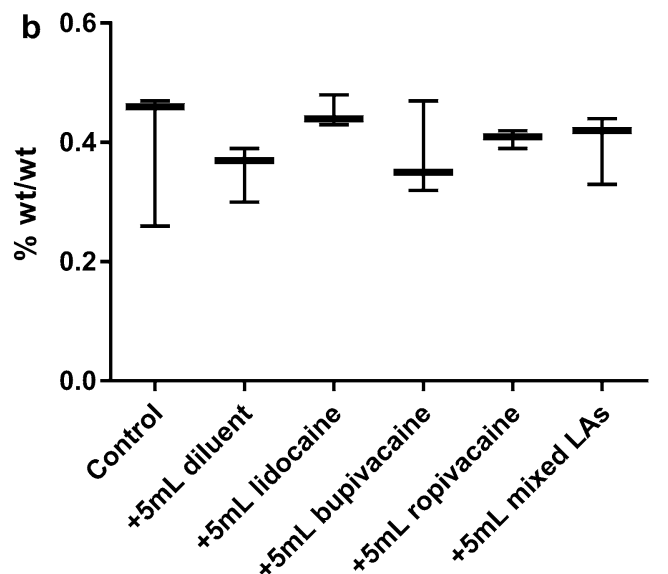


Table 3 Particle size distribution results

\begin{tabular}{llll}
\hline Sample $^{\mathbf{a}}$ & \multicolumn{2}{l}{ Particle size distribution $(\boldsymbol{\mu} \mathbf{m})($ mean $\mathbf{\pm} \mathbf{S D})$} \\
\cline { 2 - 4 } & $\mathbf{D V}_{\mathbf{1 0}}$ & $\mathbf{D V}_{\mathbf{5 0}}$ & $\mathbf{D V}_{\mathbf{9 0}}$ \\
\hline Control & $23 \pm 0$ & $38 \pm 1$ & $64 \pm 4$ \\
$+5 \mathrm{~mL}$ diluent & $22 \pm 1$ & $38 \pm 1$ & $67 \pm 5$ \\
$+5 \mathrm{~mL}$ lidocaine & $22 \pm 0$ & $37 \pm 0$ & $61 \pm 1$ \\
$+5 \mathrm{~mL}$ bupivacaine & $22 \pm 0$ & $37 \pm 0$ & $63 \pm 1$ \\
$+5 \mathrm{~mL}$ ropivacaine & $22 \pm 1$ & $38 \pm 0$ & $64 \pm 1$ \\
$+5 \mathrm{~mL}$ mixed local anesthetic & $22 \pm 1$ & $38 \pm 1$ & $64 \pm 2$ \\
\hline
\end{tabular}

$S D$ standard deviation

${ }^{a} n=3$ replicates per sample type

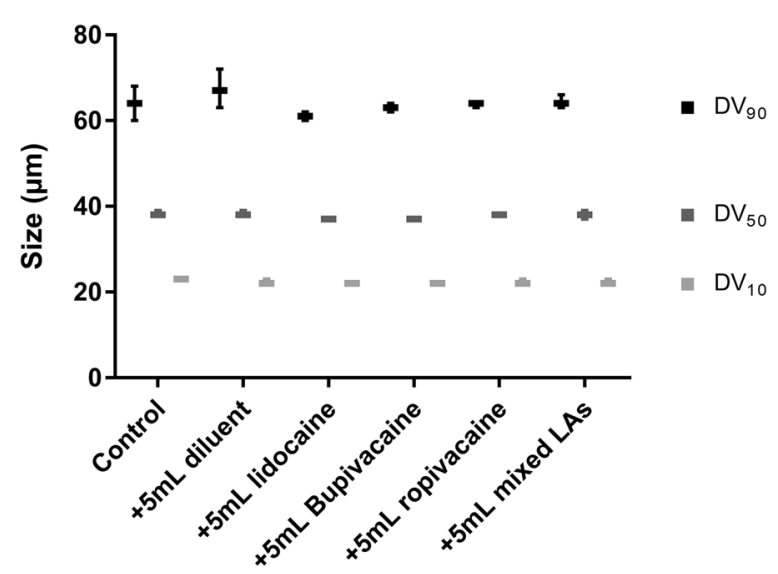

Fig. 3 Particle size distribution results. $L A$ local anesthetic

\section{Optical Microscopy}

Optical microscopy results are presented in Fig. 4. No differences in agglomeration or aggregation were observed with the addition of local anesthetic solutions.

\section{DISCUSSION}

In clinical practice, lidocaine, bupivacaine, and/ or ropivacaine are commonly added to IA corticosteroid injection solutions, including TA $[6,7,16,19-22,24-26]$. In this study, we assessed the impact of adding various local anesthetics to the injection suspension of
TA-ER, a novel, extended-release formulation of TA. Physical and chemical compatibility of the mixture was assessed by measuring syringeability, $\mathrm{pH}$, particle size, physical appearance, purity, and percentage free drug assays. Prior studies of local anesthetic absorption kinetics demonstrate rapid dissemination of drug from the injection site $[6,10-13]$. Therefore, the effects of local anesthetic on TA-ER molecules would be greatest during the process of preparing the injection solution. In this study, a 30 -min incubation was used to provide ample time to observe any negative effects of local anesthetic on the TA-ER molecules and drug release.

Mixtures of local anesthetic solutions with reconstituted TA-ER did not demonstrate physical or chemical changes in the TA-ER formulation. These results are consistent with commonly used injection preparations for the treatment of $\mathrm{OA}$ and previous in vitro analyses of mixing steroid preparations and local anesthetic solutions $[6,17,24,25]$. The addition of a local anesthetic to TA-ER preparations results in a $10-\mathrm{mL}$ injection volume, which is consistent with the 5- to $10-\mathrm{mL}$ IA injection volumes commonly used in clinical practice $[7,9,16,20-22]$.

There were limitations to this study, including the evaluation of mixtures at only the 30-min time point after combination. The time limit of $30 \mathrm{~min}$ was based on the standard 


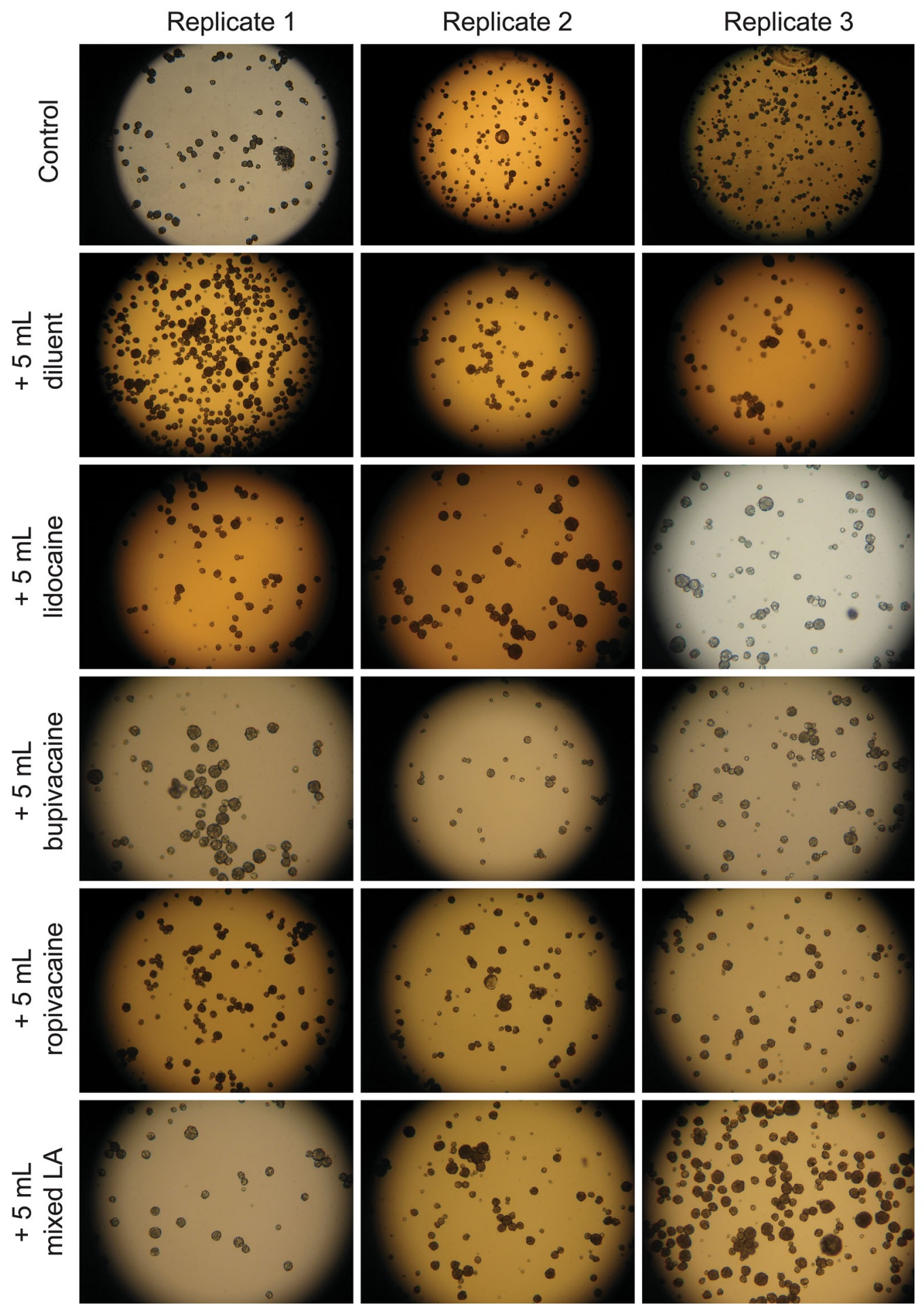

Fig. 4 Qualitative microscopy results. $L A$ local anesthetic

practice of reconstitution and preparation of corticosteroid solutions immediately prior to injection. According to the TA-ER instructions for use, the reconstituted TA-ER suspension can be stored within the vial for up to $4 \mathrm{~h}$ [32]. However, once the TA-ER preparation is pulled 
into the syringe it should be immediately administered. This study did not assess TA-ER reconstitution in the local anesthetic solution, as TA-ER instructions for use specify using the product-specific diluent for proper wetting, dispersion, and dosing of TA-ER. TA-ER should not be reconstituted directly in local anesthetic solutions.

\section{CONCLUSIONS}

Adding local anesthetic to the TA-ER injection solution does not result in demonstrable physical or chemical changes, which is consistent with the clinical experience of adding local anesthetic solutions to other corticosteroid preparations.

\section{ACKNOWLEDGEMENTS}

The authors wish to acknowledge Amanda Berry and Emmanuel Tejada of Alcami Corporation (Wilmington, NC, USA) for their significant experimental contributions to this paper.

Funding. This work was supported by Flexion Therapeutics, Inc. Article processing charges were funded by Flexion Therapeutics, Inc. All authors had full access to all of the data in this study and take complete responsibility for the integrity of the data and accuracy of the data analysis.

Medical Writing and/or Editorial Assistance. Professional medical writing and editing assistance was provided by Kathleen Richards, $\mathrm{PhD}$ (ApotheCom, Yardley, PA, USA); this support was funded by Flexion Therapeutics, Inc. (Burlington, MA, USA).

Authorship. All named authors meet the International Committee of Medical Journal Editors (ICMJE) criteria for authorship for this article, take responsibility for the integrity of the work as a whole, and have given their approval for this version to be published.
Author Contributions. All authors were involved in drafting the article or revising it critically for important intellectual content; provided final approval of the version to be submitted/published; and agreed to be accountable for all aspects of the work in ensuring that questions related to the accuracy or integrity of any part of the work are appropriately investigated and resolved.

Disclosures. J. Derek Jackson is an employee of Flexion Therapeutics, Inc. Lindsey Cotton is an employee of Flexion Therapeutics, Inc. Melinda Turkington is an employee of Flexion Therapeutics, Inc. Daniel Leblanc is an employee of Flexion Therapeutics, Inc. Scott Kelley is an employee of Flexion Therapeutics, Inc.

Compliance with Ethics Guidelines. This article does not contain any studies with human participants or animal studies performed by any of the authors.

Data Availability. All data generated or analyzed during this study are included in this published article/as supplementary information files.

Open Access. This article is distributed under the terms of the Creative Commons Attribution-NonCommercial 4.0 International License (http://creativecommons.org/licenses/ by-nc/4.0/), which permits any noncommercial use, distribution, and reproduction in any medium, provided you give appropriate credit to the original author(s) and the source, provide a link to the Creative Commons license, and indicate if changes were made.

\section{REFERENCES}

1. Murray CJ, Atkinson C, Bhalla K, et al. The state of US health, 1990-2010: burden of diseases, injuries, and risk factors. JAMA. 2013;310:591-608.

2. CDC. Osteoarthritis basics. 2018. https://www.cdc. gov/arthritis/basics/osteoarthritis.htm. Accessed 25 Jun 2018. 
3. Dominick KL, Ahern FM, Gold $\mathrm{CH}$, Heller DA. Health-related quality of life among older adults with arthritis. Health Qual Life Outcomes. 2004;2:5.

4. Lawrence RC, Felson DT, Helmick CG, et al. Estimates of the prevalence of arthritis and other rheumatic conditions in the United States. Part II. Arthritis Rheum. 2008;58:26-35.

5. Mushtaq S, Choudhary R, Scanzello CR. Non-surgical treatment of osteoarthritis-related pain in the elderly. Curr Rev Musculoskelet Med. 2011;4:113-22.

6. MacMahon PJ, Eustace SJ, Kavanagh EC. Injectable corticosteroid and local anesthetic preparations: a review for radiologists. Radiology. 2009;252:647-61.

7. Jorgensen TS, Graven-Nielsen T, Ellegaard K, Danneskiold-Samsoe B, Bliddal $\mathrm{H}$, Henriksen M. Intraarticular analgesia and steroid reduce pain sensitivity in knee OA patients: an interventional cohort study. Pain Res Treat. 2014;2014:710490.

8. Lavelle W, Lavelle ED, Lavelle L. Intra-articular injections. Anesthesiol Clin. 2007;25:853-62.

9. Rifat SF, Moeller JL. Injection and aspiration techniques for the primary care physician. Compr Ther. 2002;28:222-9.

10. Ala-Kokko TI, Karinen J, Raiha E, Kiviluoma K, Alahuhta S. Pharmacokinetics of $0.75 \%$ ropivacaine and $0.5 \%$ bupivacaine after ilioinguinal-iliohypogastric nerve block in children. Br J Anaesth. 2002;89:438-41.

11. Katz JA, Kaeding CS, Hill JR, Henthorn TK. The pharmacokinetics of bupivacaine when injected intra-articularly after knee arthroscopy. Anesth Analg. 1988;67:872-5.

12. Richards MM, Maxwell JS, Weng L, Angelos MG, Golzarian J. Intra-articular treatment of knee osteoarthritis: from anti-inflammatories to products of regenerative medicine. Phys Sportsmed. 2016;44:101-8.

13. Arthur GR, Feldman HS, Covino BG. Comparative pharmacokinetics of bupivacaine and ropivacaine, a new amide local anesthetic. Anesth Analg. 1988;67:1053-8.

14. Barry SL, Martinez SA, Davies NM, Remsberg CM, Sayre CL, Bachelez A. Synovial fluid bupivacaine concentrations following single intra-articular injection in normal and osteoarthritic canine stifles. J Vet Pharmacol Ther. 2015;38:97-100.
15. Dragoo JL, Korotkova T, Kanwar R, Wood B. The effect of local anesthetics administered via pain pump on chondrocyte viability. Am J Sports Med. 2008;36:1484-8.

16. Juni P, Hari R, Rutjes AW, et al. Intra-articular corticosteroid for knee osteoarthritis. Cochrane Database Syst Rev. 2015:CD005328.

17. Stephens MB, Beutler AI, O'Conner FG. Musculoskeletal injections: a review of the evidence. Am Fam Physician. 2008;78:971-6.

18. Caldwell JR. Intra-articular corticosteroids. Guide to selection and indications for use. Drugs. 1996;52:507-14.

19. Tammachote N, Kanitnate S, Yakumpor T, Panichkul P. Intra-articular, single-shot hylan G-F 20 hyaluronic acid injection compared with corticosteroid in knee osteoarthritis: a double-blind, randomized controlled trial. J Bone Joint Surg Am. 2016;98:885-92.

20. Soriano-Maldonado A, Klokker L, Bartholdy C, et al. Intra-articular corticosteroids in addition to exercise for reducing pain sensitivity in knee osteoarthritis: exploratory outcome from a randomized controlled trial. PLoS One. 2016;11:e0149168.

21. Beyaz SG. Comparison of efficacy of intra-articular morphine and steroid in patients with knee osteoarthritis. J Anaesthesiol Clin Pharmacol. 2012;28:496-500.

22. Sari S, Aydin ON, Turan Y, Ozlulerden P, Efe U, Kurt Omurlu I. Which one is more effective for the clinical treatment of chronic pain in knee osteoarthritis: radiofrequency neurotomy of the genicular nerves or intra-articular injection? Int J Rheum Dis. 2018;21(10):1772-1778.

23. Centeno LM, Moore ME. Preferred intraarticular corticosteroids and associated practice: a survey of members of the American College of Rheumatology. Arthritis Care Res. 1994;7:151-5.

24. Shah K, Watson D, Campbell C, Meek RM. Intraarticular injection composed of steroid, iohexol and local anaesthetic: is it stable? $\mathrm{Br} \mathrm{J}$ Radiol. 2009;82:109-11.

25. Benzon HT, Chew TL, McCarthy RJ, Benzon HA, Walega DR. Comparison of the particle sizes of different steroids and the effect of dilution: a review of the relative neurotoxicities of the steroids. Anesthesiology. 2007;106:331-8.

26. Park KD, Kim TK, Bae BW, Ahn J, Lee WY, Park Y. Ultrasound guided intra-articular ketorolac versus corticosteroid injection in osteoarthritis of the hip: 
a retrospective comparative study. Skeletal Radiol. 2015;44:1333-40.

27. Kraus VB, Conaghan PG, Aazami HA, et al. Synovial and systemic pharmacokinetics (PK) of triamcinolone acetonide (TA) following intra-articular (IA) injection of an extended-release microsphere-based formulation (FX006) or standard crystalline suspension in patients with knee osteoarthritis (OA). Osteoarthritis Cartilage. 2018;26:34-42.

28. Conaghan PG, Cohen SB, Berenbaum F, Lufkin J, Johnson JR, Bodick N. Brief report: a phase IIb trial of a novel extended-release microsphere formulation of triamcinolone acetonide for intraarticular injection in knee osteoarthritis. Arthritis Rheumatol. 2018;70:204-11.

29. Conaghan PG, Hunter D, Cohen SB, et al. Effects of a single intra-articular injection of a microsphere formulation of triamcinolone acetonide on knee osteoarthritis pain. J Bone Jt Surg. 2018;100(8):666.
30. Bodick N, Lufkin J, Willwerth C, et al. An intraarticular, extended-release formulation of triamcinolone acetonide prolongs and amplifies analgesic effect in patients with osteoarthritis of the knee: a randomized clinical trial. J Bone Jt Surg Am. 2015;97:877-88.

31. ASHP. Handbook on injectable drugs. 20th ed. Bethesda: American Society of Health-System Pharmacists; 2018.

32. Zilretta-PI. Zilretta (Triamcinolone acetonide extended-release) [package insert]. Burlington, MA: Flexion Therapeutics; 2017.

33. Manallack DT, Prankerd RJ, Yuriev E, Oprea TI, Chalmers DK. The significance of acid/base properties in drug discovery. Chem Soc Rev. 2013;42:485-96.

34. Mastersizer-3000. Mastersizer 3000 smarter particle sizing (technical brochure). Malvern: Malvern Panalytical; 2018. 